\title{
Antioxidant: A New Role for RU-486 and Related Compounds
}

\author{
Sampath Parthasarathy, Arlene J. Morales, ${ }^{\star}$ and Ana A. Murphy \\ Department of Gynecology and Obstetrics, Emory University School of Medicine, Atlanta, Georgia 30322 and *Department of \\ Reproductive Medicine, University of California, San Diego, La Jolla, California 92093
}

\begin{abstract}
RU-486 (17 $\beta$-hydroxy 4-dimethylaminophenyl-17- $\alpha$-propenyl estrone 4,9 diene-3-one; mifepristone) is suggested to act by binding to progesterone and glucocorticoid receptors. Based on its chemical nature, we anticipated that RU-486 may have potent antioxidant properties. We used the oxidation of LDL as our model system. RU-486 and a similar compound, onapristone, at $1-5-\mu \mathrm{M}$ concentrations, decreased the formation of oxidized LDL. LDL isolated from plasma of subjects who were orally supplemented with RU486 was resistant to oxidation, as compared to $\mathrm{LDL}$ isolated from control plasma.

The antioxidant effect of $\mathrm{RU}-486$ appears to reside in the dimethylaminophenyl side chain moiety. Reduction of the A-ring of the steroid molecule had no effect on its antioxidant property. Analogs of RU-486 which lack the dimethylaminophenyl group, were without antioxidant activity. Levonorgestrel, which lacks the dimethylaminophenyl group failed to inhibit the oxidation of LDL even at 100- $\mu M$ levels. In contrast, ethinylestradiol and estradiol which do not possess the dimethylamino group, were able to inhibit the oxidation of LDL by virtue of their phenolic steroid "A" ring.

Thus RU-486, with its long half life, high plasma concentrations, association with lipoproteins, and ability to readily enter the cell may have additional intra- and extra-cellular antioxidant effects. (J. Clin. Invest. 1994. 94:1990-1995.) Key words: lipid peroxidation - low density lipoprotein • onapristone $\bullet$ antiprogestins $\bullet$ estradiol
\end{abstract}

\section{Introduction}

RU-486 or mifepristone is a steroid derivative that possesses potent antiprogesterone and antiglucocorticoid activities $(1,2)$. In addition to its use in the termination of pregnancy $(3,4)$, recent studies have suggested that RU-486 is effective in providing relief from pain associated with endometriosis (5), and induced a marked reduction in leiomyoma volume (6). Further-

Address correspondence to Sampath Parthasarathy, Ph.D., Dept. of Gynecology and Obstetrics, PO Box 21246, Emory University School of Medicine, Atlanta, GA 30322.

Received for publication 15 February 1994 and in revised form 14 July 1994.

1. Abbreviations used in this paper: EC, endothelial cell; ETYA, eicosatetraynoic acid; LOOH, lipid hydroperoxide; TBARS, thiobarbituric acid substances.

J. Clin. Invest.

(C) The American Society for Clinical Investigation, Inc.

0021-9738/94/11/1990/06 \$2.00

Volume 94, November 1994, 1990-1995 more, tumors that have hormone receptors, such as breast cancer and meningiomas, have been reported to respond clinically to RU-486 (7-9). Its efficacy as an antiglucorticoid also has received attention in the treatment of patients with Cushing's syndrome (10). However, agonist-like proliferative effects have also been recognized in cultured breast cancer lines and in postmenopausal women $(11,12)$. Such effects have been attributed to the presence of increased levels of cAMP (13). Despite considerable progress in the understanding of the biochemistry and molecular biology of steroid hormone receptors and the interaction of antiprogestins with the receptor $(1,2,14-17)$, very little is known about the potential nonhormonal actions of these compounds. It is efficiently absorbed from the intestine and plasma concentrations reach micromolar amounts $(1,2,18,19)$. We anticipated that RU-486 may interact with an oxidation system and may exhibit potent antioxidant properties, based on its chemical nature, its similarity to the antioxidant, Lazaroid U-74,500A (a lipophilic dimethyl- or ethyl- amino group), and the formation of mono- and di-demethylated and hydroxylated metabolic products $(20,21)$.

A plethora of evidence has suggested that oxidized LDL may play an important role in the development of arteriosclerotic lesion (22-33). This oxidation can be prevented either by the enrichment of the lipoprotein or of the cells with antioxidants $(22,23,27)$.

In this study, we demonstrate that RU-486 and similar steroid analogs such as onapristone, that have a dimethylaminophenyl group, have potent antioxidant properties. We also provide evidence to suggest that the antioxidant activity resides in the nonsteroid moiety, namely the dimethylaminophenyl group of this molecule. We show that LDL isolated from patients who were given oral doses of RU-486 is resistant to oxidation when exposed to in vitro oxidation conditions.

\section{Methods}

RU-486 was a gift from Roussel-Uclaf (Romainville, France). Onapristone and ZK 112,993 were generously provided by Schering, AG (Berlin, Germany). Ethinylestradiol and other chemicals were purchased from Sigma Chemical Co. (St. Louis, MO). The chemical structures of these compounds are given in Fig. 1. LDL was isolated from normal human donors and radioiodinated as described before $(22,23,27)$. The LDL was subjected to oxidation in the presence of $5 \mu \mathrm{M}$ copper in phosphate-buffered saline in spectrophotometric cuvettes and the increase in absorption at $234 \mathrm{~nm}$ was followed continuously up to $6 \mathrm{~h}$ (34). Oxidation incubations with copper or with endothelial cells (rabbit aortic cell line, $\mathrm{B}_{4}$ ) were followed by established procedures by incubating $100 \mu \mathrm{g} \mathrm{LDL}$ protein/ml in $2 \mathrm{ml}$ Ham's F-10 medium (22, 23, 27, 34). RU-486 and other drugs were added in $0.1 \%$ of ethyl alcohol. Aliquots were taken for thiobarbic acid products (TBARS) ${ }^{1}$ analysis and for macrophage degradation $(27,34)$. Mouse peritoneal macrophages were harvested by peritoneal lavage, and degradation incubations were carried out as described elsewhere using cells that were cultured overnight $(27,34)$. 

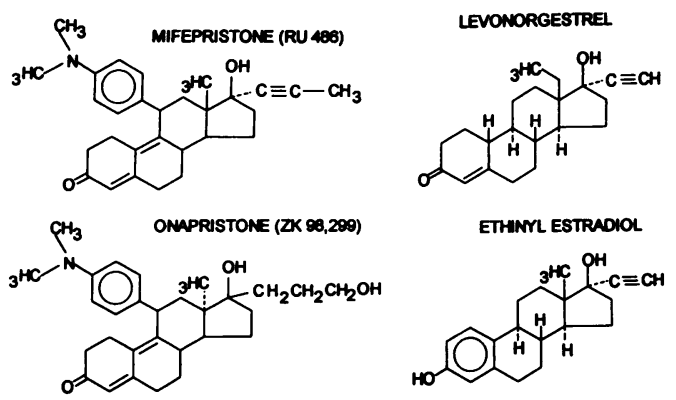

Figure 1. Structures of RU-486 and related compounds.

\section{Results}

In order to test the effect of RU-486 on the oxidation of LDL, the lipoprotein was subjected to oxidation with $5 \mu \mathrm{M}$ copper and the formation of conjugated diene was measured by following increase in absorption at $234 \mathrm{~nm}$ (34). As seen in Figs. 2 and 3, the control incubation generated an oxidized LDL that reached maximum increase in absorption at about $200 \mathrm{~min}$. The lag phase, which represents the time at which antioxidants are consumed, was $\sim 130 \mathrm{~min}$. In the presence of increasing amounts of RU-486 (Fig. 2) or onapristone (Fig. 3), there was an increased lag time, and it was apparent that even as little as 0.5 $\mu \mathrm{M}$ RU-486 was able to delay the oxidation rate. The maximum increase observed, at the end of the incubation, was not altered showing that the inhibitors did not affect the net availability of fatty acid molecules for oxidation in the system. The antioxidant effect was as potent as that observed with probucol $(27,35)$ or other phenolic oxidants, including estradiol, $(36,37)$ even though neither RU-486 nor onapristone have a phenolic function.

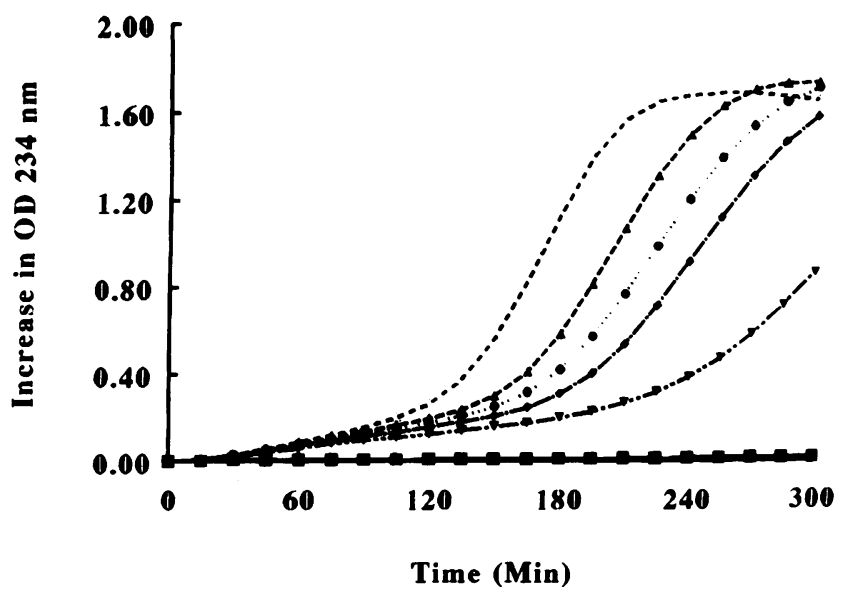

Figure 2. Effect of RU-486 on the oxidation of LDL by copper. LDL was incubated with $5 \mu \mathrm{M}$ copper in spectrophotometric cuvettes in the presence of specified concentrations of RU-486. OD at $234 \mathrm{~nm}$ was monitored continuously for $300 \mathrm{~min}$. The figure represents results from a typical experiment from over six individual experiments. ( $\square--$, control LDL without copper; - - -, LDL incubated with $5 \mu \mathrm{M}$ copper; $\triangle$ - -, LDL incubated with $5 \mu \mathrm{M}$ copper and $0.1 \mu \mathrm{M}$ RU-486; - - , LDL incubated with $5 \mu \mathrm{M}$ copper and $0.5 \mu \mathrm{M}$ RU-486; - -, LDL incubated with $5 \mu \mathrm{M}$ copper and $1.0 \mu \mathrm{M}$ RU-486; $\nabla$ - -, LDL incubated with 5 $\mu \mathrm{M}$ copper and $2.5 \mu \mathrm{M}$ RU-486.)

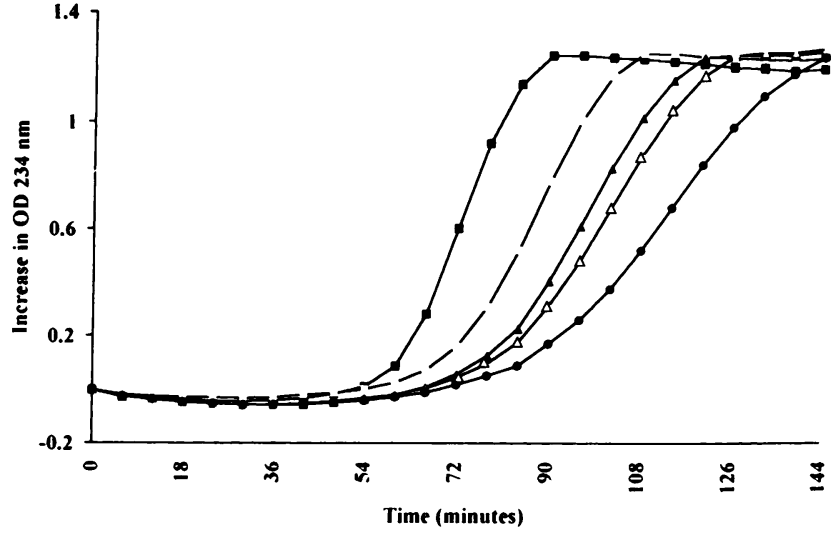

Figure 3. Effect of onapristone on the oxidation of LDL by copper. LDL was incubated with $5 \mu \mathrm{M}$ copper in spectrophotometric cuvettes in the presence of specified concentrations of onapristone. OD at 234 $\mathrm{nm}$ was monitored continuously for $300 \mathrm{~min}$. The figure represents results from a typical experiment from over six individual experiments. ( $\square-$-, LDL incubated with $5 \mu \mathrm{M}$ copper; - - -, LDL incubated with 5 $\mu \mathrm{M}$ copper and $1 \mu \mathrm{M}$ onapristone; $\Delta--$, LDL incubated with $5 \mu \mathrm{M}$ copper and $2 \mu \mathrm{M}$ onapristone; $\Delta--$, incubated with $5 \mu \mathrm{M}$ copper and 3 $\mu \mathrm{M}$ onapristone; $\bullet-$-, LDL incubated with $5 \mu \mathrm{M}$ copper and $4 \mu \mathrm{M}$ onapristone.)

The efficiency of RU-486 in inhibiting the oxidative modification of the LDL was studied using ${ }^{125}$ I-labeled lipoprotein. LDL incubated with endothelial cells showed more than 2.5fold increase in the electrophoretic mobility as compared to the control LDL. RU-486 decreased the formation of a more electronegative LDL. Similarly, the increase in mobility of LDL seen when LDL was oxidized with copper was also decreased by RU-486 (Table I). The formation of TBARS is a convenient

Table I. Effect of $R U-486$ on the Oxidative Modification of $L D L$ by Endothelial Cells and Copper

\begin{tabular}{|c|c|c|c|}
\hline \multirow[b]{2}{*}{ Sample } & \multirow{2}{*}{$\begin{array}{l}\text { Relative mobility } \\
\text { (CM) }\end{array}$} & \multicolumn{2}{|c|}{$\begin{array}{l}\text { Macrophage degradation } \\
\mu \mathrm{g} / 5 \mathrm{~h} \text { per mg cell protein }\end{array}$} \\
\hline & & Medium & Cell associated \\
\hline Native LDL & 0.9 & 0.4 & 0.5 \\
\hline LDL incubated with EC & 2.5 & 6.2 & 9.6 \\
\hline \multicolumn{4}{|l|}{$\begin{array}{c}\text { EC-LDL prepared in } \\
\text { the presence of }\end{array}$} \\
\hline $2 \mu \mathrm{M}$ RU-486 & 2.2 & 4.0 & 6.0 \\
\hline $5 \mu \mathrm{M}$ RU-486 & 1.7 & 1.9 & 2.9 \\
\hline $\mathrm{Cu}-\mathrm{LDL}$ & 2.4 & 6.9 & 10.3 \\
\hline \multicolumn{4}{|l|}{$\begin{array}{l}\mathrm{Cu}-\mathrm{LDL} \text { prepared in the } \\
\text { presence of }\end{array}$} \\
\hline $2 \mu \mathrm{M}$ RU-486 & 1.7 & 1.9 & 2.8 \\
\hline $5 \mu \mathrm{M}$ RU-486 & 1.3 & 1.3 & 2.7 \\
\hline
\end{tabular}

${ }^{125} \mathrm{I}-\mathrm{LDL}(100 \mu \mathrm{g} / \mathrm{ml})$ was incubated with confluent endothelial cells or with $5 \mu \mathrm{M}$ copper in Ham's F-10 medium in 60-mm dishes for $24 \mathrm{~h}$ at $37^{\circ} \mathrm{C}$. The medium was harvested and tested for TBARS, electrophoretic mobility, and macrophage degradation. The values represent the average of a duplicate set of determinations from a representative experiment. Four independent experiments were performed in which the degree of inhibition varied $\pm 14 \%$. 
Table II. Effect of $R U-486$ and Reduced $R U-486$ on the Oxidative Modification of $L D L$ by $5 \mu M$ Copper

\begin{tabular}{lcc}
\hline & \multicolumn{2}{c}{$\begin{array}{c}\text { Macrophage uptake } \mu \mathrm{g} / 5 \mathrm{~h} \\
\text { per mg cell protein }\end{array}$} \\
\cline { 2 - 3 } \multicolumn{1}{c}{ Sample } & Degradation & Cell associated \\
\hline Native LDL & 1.3 & 1.1 \\
$\mathrm{Cu}-\mathrm{LDL}$ & 5.4 & 4.1 \\
Cu-LDL prepared in the & & \\
$\quad$ presence of & & 1.4 \\
$2 \mu$ M RU-486 & 1.2 & 1.3 \\
$5 \mu$ M RU-486 & 0.9 & \\
Cu-LDL prepared in the & & 1.0 \\
$\quad$ presence of & & 1.2 \\
$2 \mu$ M Reduced RU-486 & 0.8 & \\
$5 \mu$ M Reduced RU-486 & 0.6 & \\
& & \\
\hline
\end{tabular}

${ }^{125} \mathrm{I}-\mathrm{LDL}(100 \mu \mathrm{g} / \mathrm{ml})$ was incubated with confluent endothelial cells or with $5 \mu \mathrm{M}$ copper in Ham's F-10 medium in $60-\mathrm{mm}$ dishes for $24 \mathrm{~h}$ at $37^{\circ} \mathrm{C}$. The medium was harvested and tested for TBARS and macrophage degradation. The values represent average of a duplicate set of determinations from a representative experiment. Two separate experiments were performed.

means of measuring lipid peroxidation. The LDL incubated with $5 \mu \mathrm{M}$ copper generated over $55 \mathrm{nmol}$ of TBARS and was efficiently degraded by the macrophages. Addition of 2-5 $\mu \mathrm{M}$ RU-486 decreased the formation of TBARS and decreased the degradation by macrophages. This was not due to the effect of RU-486 on the intracellular metabolism of oxidized LDL in macrophages, as the cell-associated radioactivity or accumulation of oxidized LDL in macrophages was also decreased. The degradation of the LDL incubated in the presence of RU-486 during oxidation was similar to that of the control LDL, incubated in the absence of copper.

In order to test whether the antioxidant effect was due to the progesterone ring, RU-486 was subjected to reduction using sodium borohydride. The reduced RU-486 was still as effective as RU-486 in inhibiting the oxidation of LDL showing almost similar lag phases as compared to the unreduced RU-486 (data

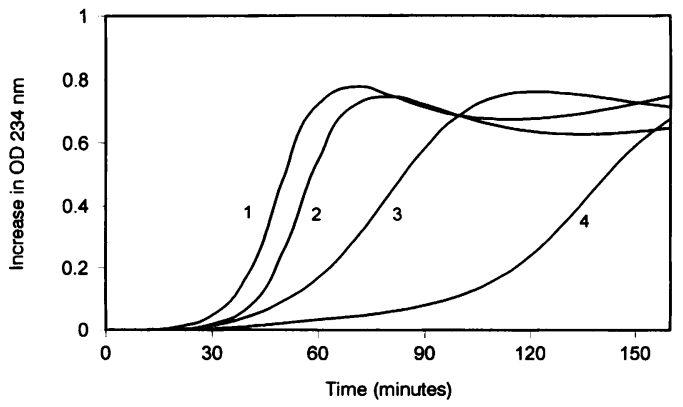

Figure 4. Effect of ZK 112993 on the oxidation of LDL. LDL was incubated with $5 \mu \mathrm{M}$ copper in spectrophotometric cuvettes in a total volume of $1 \mathrm{ml}$ of PBS in the presence or absence of ZK 112993 or RU-486. The formation of conjugated dienes was followed by measuring the increase in absorption at $234 \mathrm{~nm}$. The figure represents results from a typical experiment from three individual experiments. 1 , control incubation; 2, incubation in the presence of $10 \mu \mathrm{M} \mathrm{ZK} \mathrm{112993;} 3$ and 4, incubation in the presence of 0.5 and $1 \mu \mathrm{M}$ RU-486.

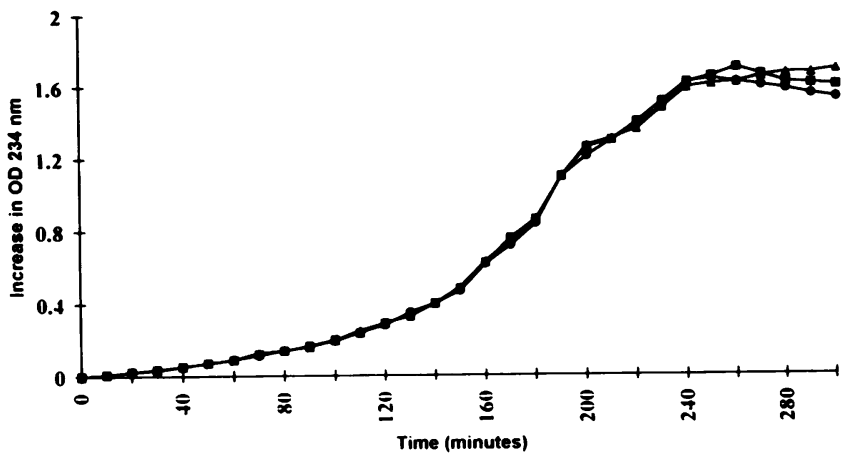

Figure 5. Effect of levonorgestrel on the oxidation of LDL by copper. LDL was incubated with $5 \mu \mathrm{M}$ copper in spectrophotometric cuvettes in the presence of specified concentrations of levonorgestrel. OD at 234 $\mathrm{nm}$ was monitored continuously for $300 \mathrm{~min}$. The figure represents results from a typical experiment from three individual experiments. $(\Lambda--$, control incubation in the absence of levonorgestrel; $\square--$, incubation in the presence of $5 \mu \mathrm{M}$ levonorgestrel; $\bullet--$, incubation in the presence of $10 \mu \mathrm{M}$ levonorgestrel.)

not given). As shown in Table II, the inclusion of reduced RU486 also prevented the formation of TBARS and macrophage degradation, suggesting again that the progesterone ring does not contribute to the antioxidant effect of RU-486. In fact, the reduced RU-486 was even more active as an antioxidant than RU-486 itself. Similar effects were noted when reduced RU486 was incubated in a cell oxidation system utilizing mouse macrophages (results not shown).

RU-486 also has a side chain that contains a propenyl group. This propenyl group is an acetylenic bond similar to that found in the lipoxygenase inhibitor and antioxidant, namely eicosatetraynoic acid (ETYA). In order to distinguish whether the propenyl group contributes to the antioxidant effect or the antioxidant effect is due to the dimethyl aminophenyl group, we utilized two other compounds, levonorgestrel and ZK 112,993. These compounds are similar to RU-486, except that the dimethylaminophenyl group is replaced by a hydrogen atom and a acetophenyl side chain, respectively. These compounds did not show any significant antioxidant effects even at $10-\mu \mathrm{M}$ levels (Figs. 4 and 5). The addition of $10 \mu \mathrm{M} \mathrm{ZK} \mathrm{112,993} \mathrm{increased} \mathrm{the} \mathrm{lag}$

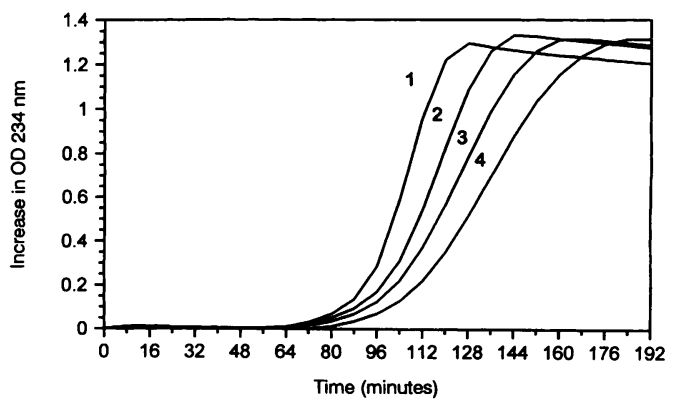

Figure 6. Effect on $N, N^{\prime}$-dimethylaniline on the oxidation of LDL. LDL was incubated with $5 \mu \mathrm{M}$ copper in spectrophotometric cuvettes in the presence of specified concentrations of dimethylanilinelevonorgestrel. $\mathrm{OD}$ at $234 \mathrm{~nm}$ was monitored continuously for $300 \mathrm{~min}$. The figure represents results from a typical experiment from a duplicate set of experiments. Numbers represent incubations that contained $0,2,4$, and $6 \mu \mathrm{M} N, N^{\prime}$-dimethylaniline. 


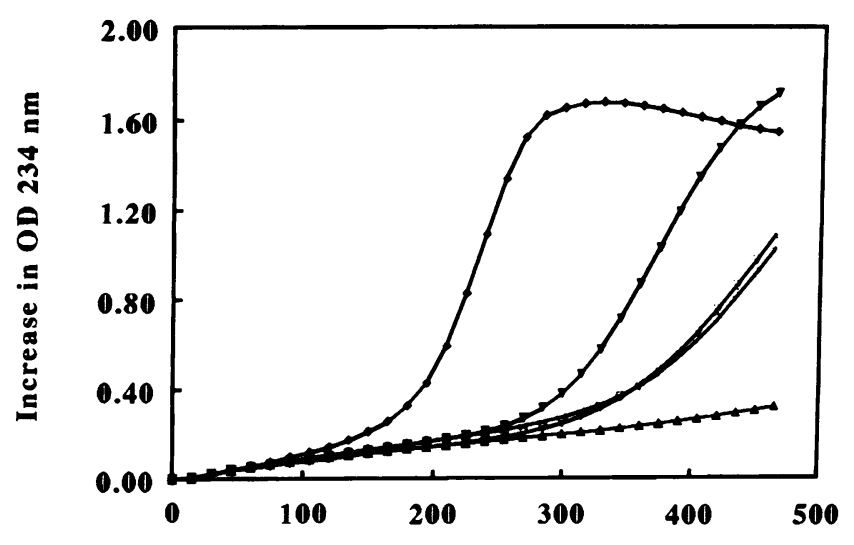

Time (minutes)

Figure 7. Effects of RU-486 and Ethinylestradiol on the oxidation of LDL by copper. LDL was incubated with $5 \mu \mathrm{M}$ copper in spectrophotometric cuvettes in the presence of specified concentrations of RU-486 or ethinylestradiol. OD at $234 \mathrm{~nm}$ was monitored continuously for 500 $\mathrm{min}$. The figure represents results from a typical experiment from four individual experiments. ( $\bullet--$, control incubation; $0--$, incubated with $2.5 \mu \mathrm{M}$ RU-486; $\Delta-$-, incubated with $5 \mu \mathrm{M}$ RU-486; $\nabla$ - -, incubated with $2.5 \mu \mathrm{M}$ ethinylestradiol; $\nabla--$, incubated with $5 \mu \mathrm{M}$ ethinylestradiol.)

phase by less than 5 min. The addition of $1 \mu \mathrm{M}$ RU-486, on the other hand, tripled the lag phase. In contrast, clomiphene and $N, N^{\prime}$-dimethylaniline, nonsteroid compounds with diethyland dimethylamino groups, respectively, were effective in decreasing the oxidation of LDL (Fig. 6). However, dimethylaniline was not as potent as RU-486 as an antioxidant, which may suggest additional factors such as solubility in a lipid environment. The lack of effect of levonorgestrel or ZK 112,993 was not due to a counteracting effect of the propenyl group in these compounds. As a control, we used ethinyl estradiol, which also possesses the propenyl group in addition to a phenolic hydroxyl group, and found it was capable of inhibiting the oxidation of the LDL (Fig. 7). Taken together, these results suggest that neither the progesterone ring nor the acetylenic triple bond themselves contributed to the antioxidant property. However, the dimethylaminophenyl group of RU-486 may provide an important antioxidant center for the molecule. The phenolic compound ethinyl estradiol inhibited the oxidation of LDL as expected.

Single dose studies have suggested that in human serum RU-486 is bound to $\alpha$-1-acid glycoprotein and the plasma concentration may be limited by the saturation of this protein ( 2 , 18). On the other hand, onapristone does not appear to bind to this protein (1). However, its lipophilicity, may suggest that it may also be carried in lipoprotein fractions in the plasma, particularly upon long term administration. In order to test whether RU-486 is indeed carried in the lipoproteins, we isolated the LDL from two subjects who consumed $25 \mathrm{mg}$ of RU486 for 8 wk (studies of RU-486 for the treatment of endometriosis and leiomyomata were approved by the internal review board of the University of California, San Diego). LDL was also isolated from control subjects. The plasma from the RU486 treated subjects had 7.3 and $11.7 \mathrm{~nm}$ of $\mathrm{RU}-486 / \mathrm{ml}$ as determined by spectroscopic methods. When subjected to oxidation, the LDL isolated from the RU-486 subjects was very resis-

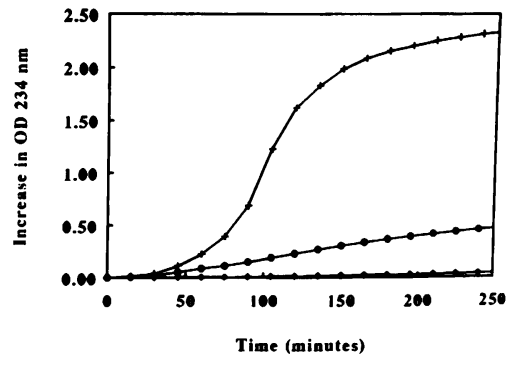

Figure 8. Oxidation of LDL from RU-486 subjects. LDL was isolated from two subjects who consumed RU-486, and was subjected to oxidation as described in the text. Two independent determinations were performed. $x--$, LDL from two control subjects; • and $\bullet--$, LDL from RU486 subjects.

tant to oxidation in the presence of copper and showed lag phases approximately three to four times higher than the control (Fig. 8).

The inhibition of LDL oxidation by antioxidant enriched cells has been reported using an analog of probucol (27). RU486 readily enters the cell and its site of antihormonal action is intracellular $(1,3,11,12)$. We, therefore, incubated RAW macrophage cells with RU-486 for $8 \mathrm{~h}$ and tested the ability of these cells to oxidize LDL after washing. As seen in Table III, cells that were incubated with LDL in Ham's F-10 medium in the presence of RU-486 oxidized the lipoprotein poorly. Since the cells were pretreated with RU-486 and no free RU-486 remained in the medium during the incubation with LDL, this may suggest that RU-486 may afford additional protection against oxidative damage to cells.

\section{Discussion}

These studies indicate that RU-486 is clearly an antioxidant and may also have other effects, unrelated to its antiprogesterone or antiglucocorticoid effects. Its ability to inhibit the oxidation of LDL by copper in an in vitro system may suggest that its antioxidant activity may also be manifested in plasma compartment, unrelated to its antiprogesterone and antiglucocorticoid effects. Similar compounds, Lazaroids, particularly U-74,500A (38-40) have been found to be effective in controlling oxidation in cells and tissues that are independent of sterol regulation. However, U-74,500A, by virtue of its steroid nucleus is effective against proliferation of breast cancer cells, suggesting that the antioxidant property of RU-486 or onapristone may play an important role in its efficacy against breast cancer.

Detailed analysis of the molecular mechanisms by which

Table III. Oxidation of LDL by Cells Pretreated with $R U-486$

\begin{tabular}{lc}
\hline \multicolumn{1}{c}{ Incubation conditions } & TBARS (\% control) \\
\hline Untreated cells & 100 \\
Cells treated with vehicle alone & $98 \pm 3$ \\
Cells pretreated with $25 \mu \mathrm{M}$ RU-486 & $59 \pm 11$ \\
Cell pretreated with $50 \mu \mathrm{M}$ RU-486 & $23 \pm 9$
\end{tabular}

Confluent RAW cells were washed and preincubated with RU-486 for $8 \mathrm{~h}$ at $37^{\circ} \mathrm{C}$. The cells were washed and subsequently incubated, in the absence of RU-486, with $100 \mu \mathrm{g} / \mathrm{ml} \mathrm{LDL}$ for an additional $24 \mathrm{~h}$ in Ham's F-10 medium. The medium was analyzed for TBARS. The values represent mean $\pm \operatorname{SD}(n=4)$. 
RU-486 affects progesterone receptor-mediated transcriptional regulation has failed to show any major differences between progesterone and its antagonists $(1,2,14-17)$. The steroidmediated activation of gene transcription appears to involve a dual component transcription function of the receptors, a hormone-dependent and a hormone-independent (41-43) component. It is possible that the antioxidant component of RU-486 may also affect the hormone-independent interactions. Recently it was suggested that the presence of cAMP adversely affects the antagonist action of RU-486 and similar antiprogestins (13). Upon increasing the cellular levels of cAMP, antagonist-coupled progesterone receptors became strong transcriptional activators suggesting cAMP-responsive factors. Agents that elevate cAMP also activate nuclear factors, particularly $\mathrm{NF} \kappa \mathrm{B}(44,45)$ and antioxidants protect cells against oxidative stress and prevent or regulate gene expression, particularly those that have regulatory domains available to nuclear factor NF $\kappa \mathrm{B}(46-48)$. Thus the possibility that free or bound, intracellular RU-486, would suppress mechanisms by which intracellular cAMP and NF $\kappa$ B are elevated thereby further decreasing transcription appears promising.

The interaction of RU-486, an amino compound, with oxygen radicals is not surprising. Compounds such as diphenylphenylenediamine (DPPD) (31), the lazaroids (38-40), have been in use as antioxidants to prevent the oxidation of LDL. Demethylation of amines is a characteristic oxidation reaction $(49,50)$ and in vivo, such reactions characterize detoxification reactions. Major metabolism of RU-486 occurs via demethylation and hydroxylation reactions $(20,21)$. Indeed, a cytochrome P-450 isozyme system has been described that catalyzes these reactions, suggesting that RU-486 may indeed be capable of interacting with an oxidation system (51). In conclusion, the finding that RU-486 and related compounds are potent antioxidants may suggest additional, potential therapeutic applications, as these compounds have already been tested for their safety and effectiveness. In fact, tomoxifen, another antiestrogen with a diethylaminogroup was recently shown to inhibit the oxidation of LDL at $\mu \mathrm{M}$ concentrations (52). More over glucocorticoids affect the expression of the acetyl LDL receptor, a receptor that recognizes among other ligands, oxidized LDL and bacterial lipopolysaccharides $(53,54)$. RU-486 with its antioxidant and antiglucocorticoid action will significantly alter the course of oxidation and macrophage function. It is difficult to assess how important this property is in mediating the anti-hormonal action; however, their ready entry into cellular compartments provides a significant advantage over existing lipophilic antioxidants.

\section{Acknowledgments}

We thank Dr. Chu-Ying Luo for assistance in cell culture experiments. This work was supported by grant HL-14197 from the National Heart, Lung, and Blood Institute, (during the tenure of S. Parthasarathy at the University of California, San Diego) and by the generous startup funds from the Department of Gynecology and Obstetrics at the Emory University.

\section{References}

1. Baulieu, E. E. 1993. RU-486-A decade on today and tomorrow. In Clinical Applications of Mifepristone RU-486 and Other Antiprogestins. M. S. Donaldson, L. Dorflinger., S. S. Brown, and L. Z. Benet, editors. National Academy Press, Washington, DC. 71-119.
2. Heikinheimo, O., and R. Kekkonen. 1993. Dose-response relationships of RU 486. Ann. Med. 25:71-76.

3. Bygdeman, M., and M. L. Swahn. 1985. Progesterone receptor blockage. Effect on uterine contractility and early pregnancy. Contraception. 32:45-51.

4. Couzinet, B., N. Le Strat, A. Ulmann, E. E. Baulieu, and G. Schaison. 1986. Termination of early pregnancy by the progesterone antagonist RU 486 (Mifepristone). N. Engl. J. Med. 315:1565-1570.

5. Kettel, L. M., A. A. Murphy, J. F. Mortola, J. H. Liu, A. Ulmann, and S. S. Yen. 1991. Endocrine responses to long-term administration of the antiprogesterone RU 486 in patients with pelvic endometriosis. Fertil. Steril. 56:402-407.

6. Murphy, A. A., L. M. Kettel, A. J. Morales, V. J. Roberts, S. S. and Yen. 1993. Regression of uterine leiomyomata in response to the antiprogesterone RU 486. J. Clin. Endocrinol. Metab. 76:513-517.

7. Bakker, G. H., B. Setyono Han, H. Portengen, F. H. de Jong, J. A. Foekens, and J. G. Klijn. 1990. Treatment of breast cancer with different antiprogestins: preclinical and clinical studies. J. Steroid Biochem. Mol. Biol. 37:789-794.

8. Bardon, S., F. Vignon, D. Chalbos, and H. Rochefort. 1985. RU 486, a progestin and glucocorticoid antagonist, inhibits the growth of breast cancer cells via the progesterone receptor. J. Clin. Endocrinol. Metab. 60:692-697.

9. Grunberg, S. M., M. H. Weiss, I. M. Spitz, J. Ahmadi, A. Sadun, C. A Russell, L. Lucci, and L. L. Stevenson. 1991. Treatment of unresectable meningiomas with the antiprogesterone agent mifepristone. J. Neurosurg. 74:861-866.

10. Nieman, L. K., G. P. Chrousos, C. Kellner, I. M. Spitz, B. C. Nisula, G. B. Cutler, G. R. Merriam, C. W. Bardin, and D. L. Loriaux. 1985. Successful treatment of Cushing's syndrome with the glucocorticoid antagonist RU 486. $J$. Clin. Endocrinol. Metab. 61:536-540.

11. Bowden, R. T., J. R. Hissom, and M. R. Moore. 1989. Growth stimulation of human T47D human breast cancer cells by the antiprogestin RU 486. Endocrinology. 124:2642-2644.

12. Gravanis, A., G. Schaison, M. George, J. de Brux, P. G. Satyaswaroop, E. E. Baulieu, and P. Robel. 1985. Endometrial and pituitary responses to the steroid antiprogestin RU 486 in postmenopausal women. J. Clin. Endocrinol. Metab. 60:156-163.

13. Sartorius, C. A., L. Tung, G. S. Takimoto, and K. B. Horwitz. 1993. Antagonist-occupied human progesterone receptors bound to DNA are functionally switched to transcriptional agonists by cAMP. J. Biol. Chem. 268:92629266.

14. Skafar, D. F. 1991. Differences in the binding mechanism of RU 486 and progesterone to the progesterone receptor. Biochemistry. 30:10829-10832.

15. Cohen Solal, K., A. Bailly, C. Rauch, M. Quesne, and E. Milgrom. 1993. Specific binding of progesterone receptor to progesterone-responsive elements does not require prior dimerization. Eur. J. Biochem. 214:189-195.

16. el Ashry, D., S. A. Onate, S. K. Nordeen, and D. P. Edwards. 1989. Human progesterone receptor complexed with the antagonist RU 486 binds to hormone response elements in a structurally altered form. Mol. Endocrinol. 3:1545-1558.

17. Gronemeyer, H., B. Benhamou, M. Berry, M. T. Bocquel, D. Gofflo, T Garcia, T. Lerouge, D. Metzger, M. E. Meyer, L. Tora, A. Vergezac, and P. Chambon. 1992. Mechanisms of antihormone action. J. Steroid Biochem. Mol. Biol. 41:217-221.

18. Heikinheimo, O., P. L. Lahteenmaki, E. Koivunen, D. Shoupe, H. Croxatto, T. Luukkainen, and P. Lahteenmaki. 1987. Metabolism and serum binding of RU 486 in women after various single doses. Hum. Reprod. (Oxf.). 2:379-385.

19. Heikinheimo, O., M. Haukkamaa, and P. Lahteenmaki. 1989. Distribution of RU 486 and its demethylated metabolites in humans. J. Clin. Endocrinol. Metab. 68:270-275.

20. Lahteenmaki, P., O. Heikinheimo, H. Croxatto, I. Spitz, D. Shoupe, L. Birgerson, and T. Luukkainen. 1987. Pharmacokinetics and metabolism of RU 486. J. Steroid Biochem. 27:859-863.

21. Zurth, C., and F. Kagels. 1990. Determination of Onapristone and its Ndesmethylated metabolite in human plasma or serum by high-performance liquid chromatography. J. Chromatog. 532:115-123.

22. Parthasarathy, S., D. Steinberg, and J. L. Witztum. 1992. The role of oxidized low-density lipoproteins in the pathogenesis of atherosclerosis. Annu. Rev. Med. 43:219-225.

23. Parthasarathy, S., and S. M. Rankin. 1992. Role of oxidized low density lipoprotein in atherogenesis. Prog. Lipid Res. 31:127-143.

24. Steinberg, D., S. Parthasarathy, T. E. Carew, J. C. Khoo, and J. L. Witztum. 1989. Beyond cholesterol. Modifications of low-density lipoprotein that increase its atherogenicity [see comments]. N. Engl. J. Med. 320:915-924.

25. Parhami, F., Z. T. Fang, A. M. Fogelman, A. Andalibi, M. C. Territo, and J. A. Berliner. 1993. Minimally modified low density lipoprotein-induced inflammatory responses in endothelial cells are mediated by cyclic adenosine monophosphate. J. Clin. Invest. 92:471-478.

26. Cushing, S. D., J. A. Berliner, A. J. Valente, M. C. Territo, M. Navab, F. Parhami, R. Gerrity, C. J. Schwartz, and A. M. Folgelman. 1990. Minimally modified low density lipoprotein induces monocyte chemotactic protein 1 in human endothelial cells and smooth muscle cells. Proc. Natl. Acad. Sci. USA. 87:5134-5138.

27. Parthasarathy, S. 1992. Evidence for an additional intracellular site of 
action of probucol in the prevention of oxidative modification of low density lipoprotein. Use of a new water-soluble probucol derivative. J. Clin. Invest. 89:1618-1621.

28. Carew, T. E., D. C. Schwenke, and D. Steinberg. 1987. Antiatherogenic effect of probucol unrelated to its hypocholesterolemic effect: evidence that antioxidants in vivo can selectively inhibit low density lipoprotein degradation in macrophage-rich fatty streaks and slow the progression of atherosclerosis in the Watanabe heritable hyperlipidemic rabbit. Proc. Natl. Acad. Sci. USA. 84:77257729.

29. Kita, T., Y. Nagano, M. Yokode, K. Ishii, N. Kume, A. Ooshima, H. Yoshida, and C. Kawai. 1987. Probucol prevents the progression of atherosclerosis in Watanabe heritable hyperlipidemic rabbit, an animal model for familial hypercholesterolemia. Proc. Natl. Acad. Sci. USA. 84:5928-5931.

30. Bjorkhem, I., A. Henriksson Freyschuss, O. Breuer, U. Diczfalusy, L. Berglund, and P. Henriksson. 1991. The antioxidant butylated hydroxytoluene protects against atherosclerosis. Arterioscler. Thromb. 11:15-22.

31. Sparrow, C. P., T. W. Doebber, J. Olszewski, M. S. Wu, J. Ventre, K. A Stevens, and Y. S. Chao. 1992. Low density lipoprotein is protected from oxidation and the progression of atherosclerosis is slowed in cholesterol-fed rabbits by the antioxidant $N, N^{\prime}$-diphenyl-phenylenediamine. J. Clin. Invest. 89:1885-1891

32. Verlangieri, A. J., and M. J. Bush. 1992. Effects of d-alpha-tocopherol supplementation on experimentally induced primate atherosclerosis. J. Am. Coll. Nutr. 11:131-138.

33. Daugherty, A., B. S. Zweifel, and G. Schonfeld. 1989. Probucol attenuates the development of aortic atherosclerosis in cholesterol-fed rabbits. Br. J. Pharmacol. 98:612-618.

34. Parthasarathy, S., J. C. Khoo, E. Miller, J. Barnett, J. L. Witztum, and D. Steinberg. 1990. Low density lipoprotein rich in oleic acid is protected agains oxidative modification: implications for dietary prevention of atherosclerosis. Proc. Natl. Acad. Sci. USA. 87:3894-3898.

35. Parthasarathy, S., S. G. Young, J. L. Witztum, R. C. Pittman, and D. Steinberg. 1986. Probucol inhibits oxidative modification of low density lipoprotein. J. Clin. Invest. 77:641-644.

36. Rifici, V. A., and A. K. Khachadurian. 1992. The inhibition of low-density lipoprotein oxidation by 17-beta estradiol. Metab. Clin. Exp. 41:1110-1114.

37. Dieber Rotheneder, M., H. Puhl, G. Waeg, G. Striegel, and H. Esterbauer. 1991. Effect of oral supplementation with D-alpha-tocopherol on the vitamin E content of human low density lipoproteins and resistance to oxidation. J. Lipid Res. 32:1325-1332.

38. Aeba, R., W. A. Killinger, R. J. Keenan, S. A. Yousem, I. Hamamoto, R. L. Hardesty, and B. P. Griffith. 1992. Lazaroid U74500A as an additive to University of Wisconsin solution for pulmonary grafts in the rat transplant model. J. Thorac. Cardiovasc. Surg. 104:1333-1339.

39. Kim, R. S., C. L. Zaborniak, A. Begleiter, and F. S. LaBella. 1992. Antiproliferative properties of aminosteroid antioxidants on cultured cancer cells. Cancer Lett. 64:61-66.
40. Singh, J. P., and P. D. Bonin. 1991. Inhibition of proliferation of fibroblasts by lazaroids (21-aminosteroids). Life Sci. 49:2053-2058.

41. Evans, R. M. 1988. The steroid and thyroid hormone superfamily. Science (Wash. DC). 240:889-895

42. Gronemeyer, H. 1991. Transcription activation by estrogen and progesterone receptors. Annu. Rev. Genet. 25:89-123.

43. Tora, L., J. White, C. Brou, D. Tasset, N. Webster, E. Scheer, and P. Chambon. 1989. The human estrogen receptor has two independent nonacidic transcriptional activation functions. Cell. 59:477-487.

44. Shirakawa, F., and S. B. Mizel. 1989. In vitro activation and nuclear translocation of NF-kappa B catalyzed by cyclic AMP-dependent protein kinase and protein kinase c. Mol. Cell. Biol. 9:2424-2430.

45. Gosh, S., and D. Baltimore. 1990. Activation of NFB by phosphorylation of its inhibitor IB. Nature (Lond.). 344:678-682.

46. Meyer, M., R. Schreck, and P. A. Baeuerle. 1993. H202 and antioxidants have opposite effects on activation of NF-kappa B and AP-1 in intact cells: AP1 as secondary antioxidant-responsive factor. EMBO (Eur. Mol. Biol. Organ.) J. 12:2005-2015.

47. Schreck, R., R. Grassmann, B. Fleckenstein, and P. A. Baeuerle. 1992 Antioxidants selectively suppress activation of NF-kappa B by human T-cell leukemia virus type I Tax protein. J. Virol. 66:6288-6293.

48. Schreck, R., K. Albermann, and P. A. Baeuerle. 1992. Nuclear factor kappa B: an oxidative stress-responsive transcription factor of eukaryotic cells (a review). Free Radical Research Communications. 17:221-237.

49. Wojtczak, A. B., K. S. Famulski, M. Buszkowska, and P. Latos. 1991 Effect of glucagon and phorbol myristate acetate on oxidative demethylation and lipid peroxidation in isolated hepatocytes. Acta Biochim. Pol. 38:251-263.

50. Jacolot, F., I. Simon, Y. Dreano, P. Beaune, C. Riche, and F. Berthou. 1991. Identification of the cytochrome P450 IIIA family as the enzymes involved in the N-demethylation of tamoxifen in human liver microsomes. Biochem. Pharmacol. 41:1911-1919.

51. Chasserot-Golaz, S., and G. Beck. 1992. How the potency of the steroid RU 486 is related to $P 450$ activities induced by dexamethasone and phenobarbital in rat hepatoma cells. J. Steroid Biochem. Mol. Biol. 41:653-657.

52. Wiseman, H., G. Paganga, C. A. Rice Evans, and B. Halliwell. 1993. Protective actions of tamoxifen and 4-hydroxytamoxifen against oxidative damage to human low-density lipoproteins: a mechanism accounting for the cardioprotective action of tamoxifen? Biochem. J. 292:635-638.

53. Moulton, K. S., H. Wu, J. Barnett, S. Parthasarathy, and C. K. Glass. 1992. Regulated expression of the human acetylated low density lipoprotein receptor gene and isolation of promoter sequences. Proc. Natl. Acad. Sci. USA 89:8102-8106.

54. Hirsch, L. J., and T. Mazzone. 1986. Dexamethasone modulates lipoprotein metabolism in cultured human monocyte-derived macrophages. Stimulation of scavenger receptor activity. J. Clin. Invest. 77:485-490. 